\title{
El Padre Hurtado, prisma para una nueva comprensión de la Responsabilidad Social
}

\author{
Jorge Aros \\ FACULTAD ECLESIÁSTICA DE TEOLOGÍA \\ PONTIFICIA UNIVERSIDAD CATÓLICA DE VALPARAÍSO \\ jorge.aros@pucv.cl
}

Resumen: El artículo propone una nueva comprensión de la Responsabilidad Social que surge desde el pensamiento de San Alberto Hurtado. Se inicia con la constatación del uso de la expresión que hace el santo chileno en su obra, para desde allí esbozar los fundamentos teológicos que lo llevan a establecer una definición de Responsabilidad Social que surge desde la responsabilidad personal y que se desarrolla en la vida pública de los creyentes. Desde esta comprensión, se pretende dar un aporte a la discusión actual sobre el tema de la Responsabilidad Social, lo que permitirá trascender el ámbito económico-empresarial en el que hoy se encuentra encarcelada la expresión.

Palabras clave: Responsabilidad Social, persona, Alberto Hurtado, Moral Social

Abstract: The article proposes a new comprehension of Social Responsabilitiy that emerges from the thought of saint Alberto Hurtado. To begin, we start with a look at the use of the expression given by the Chilean saint. From there we make a sketch of the theological foundations that bring him to establish a definition of Social Responsibility that emerges from personal responsibility and that expresses itself in the public life of the faithful. From this comprehension we intend to contribute to the present discussion about Social Responsibility, and in this way open a possibility to transcend the economical-business scope in which the expression is presently confined.

Keywords: Social Responsibility, Person, Alberto Hurtado, Social Morality 


\section{INTRODUCCIÓN}

Actualmente, la mayor parte de las reflexiones que se realizan en pro de la comprensión de la responsabilidad social están centradas en la Responsabilidad Social Empresarial (RSE) y en la Responsabilidad Social Corporativa (RSC). En ellas los planteamientos se dirigen hacia la actividad productiva de la entidad privada y pública ${ }^{1}$, con la finalidad de certificarse en este ámbito ${ }^{2}$. El problema es que escasamente estas reflexiones hacen mención a las personas que integran la empresa, invisibilizando la responsabilidad personal y relevando una responsabilidad social de un ente comunitario que, paradójicamente, por sí mismo carece de responsabilidad.

Ante este panorama, que parece desvincular a la persona de su libertad y responsabilidad, se propone en este artículo profundizar la comprensión del grado de responsabilidad social que posee la persona en particular, es decir, de qué forma cada individuo debe hacerse cargo, no solo como integrante de una organización, sino de forma personal de las consecuencias de sus actos a nivel social ${ }^{3}$. A partir de este punto, se hace necesario analizar el modo en que cada persona se enfrenta a su propia actuación social y las consecuencias de esta, pues, al centrar las reflexiones sobre la responsabilidad social solo en el aspecto empresarial, se corre el riesgo de que los individuos crean que no deben preocuparse por la connotación social de su responsabilidad personal, ya que la empresa respondería por sus actos.

Es verdad que, actualmente, surgen nuevas voces, al interior de la literatura sobre responsabilidad social en el ámbito de la empresa, que intentan remediar dicha realidad y plantear nuevas perspectivas para armonizar la RSE/RSC con la responsabilidad social personal. Tal es el

1 Cf. J. Alonso, "Mercado, valores, competencia y empresa”, en J. AlOnso (coord.), La empresa en tiempo de cambio: la RSC y los negocios inclusivos (Siglo XXI, Madrid 2012) 86-88.

2 Cf. J. Herranz, "La comunicación de la Responsabilidad Social Corporativa: usos y abusos", en F. SALINAS (ed.), Responsabilidad social de las empresas y balance social (Universidad Católica de Ávila, Ávila 2003) 96.

3 Esta realidad la constata el padre Hurtado advirtiendo que existe en la sociedad chilena una falta de conciencia sobre la responsabilidad social que cada uno de sus miembros tiene, cf. A. HurTAdo, "La psicología del adolescente contemporáneo", en V. Arancibia (ed.), Una verdadera educación. Escritos sobre educación y psicología del padre Alberto Hurtado, S. J. (Ediciones Universidad Católica de Chile, Santiago 2005) 66. 
caso de la autora Beatriz Fernández, de Economistas sin Fronteras, que plantea el traslado de la responsabilidad individual y la coherencia con los valores personales a la entidad empresarial, de modo que no es la persona la que debe adecuarse a los valores de la empresa, sino que la empresa es quien debe respetar los valores de sus integrantes, de modo que la responsabilidad social se ejecutaría por quienes la componen ${ }^{4}$. Por su parte, Cristóbal Montoro, economista y Ministro de Hacienda del gobierno español de Mariano Rajoy, plantea que la RSC ha evolucionado en la búsqueda de una armonía entre el individuo y la organización, ya que "sin conciencia/responsabilidad individual no puede haber conciencia/responsabilidad colectiva"s.

Es en este horizonte que se enmarca esta investigación, dado que, a partir de la lectura de la obra de san Alberto Hurtado Cruchaga, se puede descubrir una nueva forma de comprender la responsabilidad social, no solo centrada en la perspectiva de la institucionalidad de la empresa, sino, por sobre todo, destacando la importancia de la persona en el desarrollo de una actividad socialmente responsable ${ }^{6}$. Para Hurtado el desarrollo de la vida social de la persona, desde la perspectiva de la responsabilidad, es un valor moral $^{7}$ que determina los comportamientos del ser humano con sus semejantes ${ }^{8}$.

Para llevar adelante este propósito, de aportar a la armonización de la relación RSE/RSC y responsabilidad social personal, se explorará en los escritos del padre Hurtado el concepto de responsabilidad social, constatando la presencia del tema en toda su obra. En un segundo momento, se analizará el término responsabilidad social y se categorizará las relaciones temáticas de modo de sistematizar sus fundamentos, esbozar

4 Cf. B. FERNÁNDEZ, "Inversión socialmente responsable: de la persona a la empresa", en G. Granda (ed.), Comunicación y Gestión de la Responsabilidad Social Empresarial: claves para un desarrollo competitivo y sostenible (Cinca, Madrid 2006) 131.

5 C. Montoro, "La responsabilidad social corporativa", en J. Galán - A. SÁenz (eds.), Reflexiones sobre la responsabilidad social corporativa en el siglo XXI (Ediciones Universidad de Salamanca, Salamanca 2012) 218.

6 Cf. A. Hurtado, "Las nuevas tendencias educacionales", en V. Arancibia (ed.), Una verdadera educación. Escritos sobre educación y psicología del padre Alberto Hurtado, S. J., (Ediciones Universidad Católica de Chile, Santiago 2005) 148.

7 Cf. A. Hurtado, "Puntos de Educación", en J. Cordero (dir.), Padre Hurtado Obras Completas, t. I, (Dolmen, Santiago 22003), 267.

8 Cf. A. Hurtado, "La enseñanza de la religión en el segundo ciclo de Humanidades", en C. Rolle (ed.), Articulos de pedagogía y psicología. San Alberto Hurtado, vol. 1 (Ediciones Universidad Alberto Hurtado, Santiago 2012) 212. 
una definición y desarrollar algunas consecuencias prácticas que la responsabilidad social posee a la luz del pensamiento del padre Hurtado.

El artículo se ordenará en tres apartados. El primero da cuenta del uso que hace Alberto Hurtado del término responsabilidad social, haciendo de esta manera un examen cuantitativo de la presencia del concepto en sus distintos escritos, contextualizados en su vida apostólica. En segundo lugar, se utilizará la información anterior para dar cuenta de las fuentes teológicas de la responsabilidad social en el pensamiento de Hurtado, identificando sus fundamentos antropológicos, bíblicos y sacramentales. En tercer lugar, se esbozará una definición de responsabilidad social en base a cuatro elementos claves: la dignidad, la comunidad, la fraternidad y la participación.

\section{Uso y CONTEXTO DEL TÉRMINO RESPONSABILIDAD SOCIAL EN LOS ESCRITOS de San Alberto Hurtado}

Al momento de enfrentar el tema de la responsabilidad social en el pensamiento del padre Hurtado, es conveniente mencionar que la expresión como tal se encuentra presente quince veces en sus escritos $y$, como responsabilidades sociales, aparece otras cinco. También utiliza el término cuando alude al binomio responsabilidad personal y social, que se encuentra en tres oportunidades en sus escritos. A partir de estos pasajes donde se utiliza el concepto, se puede configurar lo que el jesuita chileno entiende como responsabilidad social y, desde allí, esbozar una definición que permita comprender la profundidad que posee el término en su pensamiento sobre el actuar social de los creyentes.

A continuación, se ordenarán las apariciones de los términos antes mencionados según las etapas propuestas por Samuel Fernández en su artículo "¿Reformar al individuo o reformar la sociedad? Un punto central en el desarrollo cronológico del pensamiento social de san Alberto Hurtado", publicado en la Revista Teología y Vida del año 2008. El doctor Fernández sistematiza los escritos del santo chileno en cuatro etapas: de 1936 a 1940 "Apostolado pedagógico"; de 1941 a 1944 "Asesor de la Acción Católica"; de 1945 a 1947 "Hogar de Cristo y formación social"; de 1948 a 1952 "Moral social y sentido de Dios".

9 Cf. S. FERNÁNDEZ, “¿Reformar al individuo o reformar la sociedad? Un punto central en el desarrollo cronológico del pensamiento social de san Alberto Hurtado”, en Teología y Vida, 49 (2008) 516. 
La expresión responsabilidad social se encuentra en los escritos del padre Hurtado que son anteriores a las etapas señaladas por el profesor Fernández, pues en su tesis doctoral de pedagogía ${ }^{10}$ titulada "El sistema pedagógico de John Dewey ante las exigencias de la Doctrina Católica" de 1935, menciona la expresión responsabilidad social ${ }^{11}$ y también la expresión responsabilidades sociales ${ }^{12}$.

En el primer período (1936-1940) emplea el término responsabilidad social tres veces, en: "Crítica al sistema filosófico de Dewey"13 (1936); "La psicología del adolescente contemporáneo y la inconsciencia"14 (1937); "Cómo remediar la desarticulación de la vida moderna"15 (1939).

En el segundo período (1941-1944) emplea en "¿Es Chile un país católico?"16 (1941) la expresión responsabilidades sociales; en "Puntos de Educación" (1942) ocupa la expresión responsabilidad social ${ }^{17}$ y también el binomio responsabilidad personal y social ${ }^{18}$; y, finalmente, en el "Informe de la educación católica en Chile" (1943), usa la expresión responsabilidad social ${ }^{19}$.

En el tercer período (1945-1947) emplea la expresión responsabilidad social en "Misión del universitario"20 (1945); en "Lo que ha de despertar la universidad en sus alumnos"21 (1945); en el "Informe al padre

10 Este texto corresponde a la fase formativa de Hurtado en la Compañía de Jesús, cf. S. FernándeZ, Escritos de San Alberto Hurtado (BAC, Madrid 2012) XXII-XXV.

11 Cf. A. Hurtado, "El sistema pedagógico de John Dewey ante las exigencias de la Doctrina Católica”, en Fundación Padre Hurtado, Padre Hurtado Obras Completas, t. 2 (Fundación Padre Hurtado, Santiago 1994) 98.

12 Cf. A. Hurtado, "El sistema pedagógico...", 124.

13 Cf. A. Hurtado, "Crítica al sistema filosófico de Dewey", en V. Arancibia (ed.), Una verdadera educación..., 252.

14 Cf. A. Hurtado, "La psicología del...", 66.

15 Cf. A. Hurtado, "Cómo remediar la desarticulación de la vida moderna", en V. ARANCIBIA (ed.), Una verdadera educación..., 91.

16 Cf. A. Hurtado, ¿Es Chile un país católico? (Los Andes, Santiago 1992) 54.

17 Cf. A. Hurtado, "Puntos de Educación...", 267.

18 Cf. A. Hurtado, "Puntos de educación...", 267.

19 Cf. A. Hurtado, "Informe de la educación católica en Chile", en V. Arancibia (ed.), Una verdadera educación..., 280.

20 Cf. A. Hurtado, "Misión del universitario", en S. Fernández (ed.), La búsqueda de Dios: Conferencias, artículos y discursos del Padre Alberto Hurtado, S.J. (Ediciones Universidad Católica de Chile, Santiago 2005) 114.

21 Cf. A. Hurtado, "Lo que ha de despertar la universidad en sus alumnos", en V. Arancibia (ed.), Una verdadera educación..., 308. 
Álvaro Lavín"22 (1947); en el "Memorial presentado al Santo Padre"23 (1947), que da cuenta de su entrevista con Pío XII; en "La enseñanza de la Religión en el Segundo ciclo de Humanidades"24 (1947), en este escrito también esgrime el binomio responsabilidad personal y social ${ }^{25}$; en "El orden social cristiano. En los documentos de la jerarquía católica" (1947) junto con responsabilidad social ${ }^{26}$, también recurre a la expresión responsabilidades sociales ${ }^{27}$ y el binomio responsabilidad personal y social28; finalmente, en su libro el "Humanismo social"29 (1947) ocupa la expresión responsabilidades sociales.

En el cuarto período, utiliza el término Responsabilidad Social en su manuscrito que se conocerá póstumamente como "Moral Social"30 (1952), publicado en el año 2004.

De este modo, se puede apreciar que el concepto Responsabilidad Social está diseminado a lo largo de la extensa obra del padre Hurtado, tanto en sus cartas, recopilaciones, charlas y otros textos. Al mismo tiempo, es posible comprobar que el mayor uso del término se desarrolla en el tercer período "el Hogar de Cristo y formación social"31; de modo que se constatan las repercusiones que tiene en su pensamiento el viaje a Estados Unidos de 1945, pues allí conoce diversas obras sociales que se-

22 Cf. A. Hurtado, "Informe al padre Álvaro Lavín de la entrevista con el Padre General”, en J. CAstellón (ed.), Cartas e informes del Padre Hurtado, S. J. (Ediciones Universidad Católica de Chile, Santiago $\left.{ }^{2} 2003\right) 196$.

23 Cf. A. Hurtado, "Memorial presentado al Santo Padre", en J. Castellón (ed.), Cartas e informes..., 201.

24 Cf. A. Hurtado, "La enseñanza de...", 200; 212.

25 Cf. A. Hurtado, "La enseñanza de...", 200.

26 Cf. A. Hurtado, El orden social cristiano. En los documentos de la jerarquía católica, t. 2 (Club de lectores, Santiago 1947) 188; 207.

27 Cf. A. Hurtado, El orden social cristiano. En los documentos de la jerarquía católica, t. 1 (Club de lectores, Santiago 1947) 193; 333.

28 Cf. A. Hurtado, "El orden social cristiano..., t. 2, 36.

29 Cf. A. Hurtado, Humanismo Social (Los Andes, Santiago 1992) 62.

30 Cf. A. Hurtado, Moral social obra póstuma del padre Alberto Hurtado, S. J., P. Miranda (ed.) (Ediciones Universidad Católica de Chile, Santiago 2004) 205.

31 Es interesante constatar que Samuel Fernández señala que en este período "los escritos de San Alberto Hurtado, hay una clara insistencia en la prioridad de la vida interior $\mathrm{y}$, a la vez, se afirma que la vida interior fundamenta y exige la preocupación social”, S. FERnÁndeZ, “¿Reformar al individuo...”, 527. 
rán fuentes de inspiración para su trabajo apostólico en Chile $^{32}$ y su viaje a Europa donde asiste a distintos congresos y encuentros que abordan la temática social ${ }^{33}$. A partir del análisis de estas fuentes, complementado con los demás escritos del santo chileno, se buscará configurar la comprensión de la responsabilidad social en el pensamiento de San Alberto y, de esa manera, aportar a la concepción de responsabilidad social que se maneja en los ámbitos empresariales y corporativos.

\section{Fundamentación teológica de la Responsabilidad Social}

En el siguiente apartado se presentará la fundamentación teológica que transversalmente sustenta el concepto de responsabilidad social en el pensamiento de San Alberto Hurtado, pues ciertamente son sus convicciones de fe las que orientan su pensamiento social ${ }^{34}$. El apartado se ordenará en tres acápites donde se trata el sustento bíblico, antropológico, y sacramental.

\subsection{Fundamentación bíblica}

Desde la perspectiva bíblica, Alberto Hurtado fundamenta la responsabilidad social en la parábola de los talentos que, para el jesuita chileno, es la parábola de la responsabilidad, pues ella manifiesta que la persona poseedora de talentos es la protagonista de la responsabilidad personal y, al donarse al prójimo, surge su dimensión social ${ }^{35}$. Desde allí, Hurtado sostiene que Dios ha entregado dones particulares a cada ser humano para que contribuya al bienestar de todos sus hermanos ${ }^{36}$. En el contexto de la formación de los jóvenes, cuando se refiere a educarlos en responsabilidad social, el santo chileno señala

"La parábola de los talentos es la parábola de la responsabilidad y habría de ser explicada con mucha frecuencia y frente a esta parábola hemos de citar el panorama de las realidades sociales que nuestros

32 Cf. M. Clavero, "Impacto y consecuencias del viaje a los Estados Unidos de 1945 en el ministerio de san Alberto Hurtado", en Teología y Vida, 51 (2010) 555-583.

33 Cf. M. Clavero, "Un punto de inflexión en la vida del Padre Alberto Hurtado. Itinerario y balance de su viaje a Europa de 1947", Teología y Vida 46 (2005) 291-320.

34 Cf. S. Fernández, “¿Reformar al individuo...”, 543.

35 Cf. A. Hurtado, "Moral social...”, 220.

36 Cf. A. Hurtado, "Cristo Rey", en S. Fernández (ed.), La buisqueda de Dios..., 184-185. 
jóvenes han de modificar con su ejemplo, con su palabra, con su acción, con su plegaria" ${ }^{37}$.

Para el padre Hurtado uno de los capítulos descuidados en la formación moral de los jóvenes de los colegios católicos es el de la responsabilidad social, pues en muchas ocasiones reconoce que se enfatiza la enseñanza sobre el fin sobrenatural del hombre, pero se desconoce la dimensión social de la fe que acompaña a su dimensión individual ${ }^{38}$. Este acento puede conducir a una ignorancia frente a la acción social que, como creyente, la persona debe realizar para la transformación de la sociedad.

De este modo, el jesuita chileno sostiene que desde el reconocimiento de la recepción de dones entregados por Dios, se puede formar en el cristiano una actitud de servicio hacia toda la humanidad y, de manera especial, hacia sus hermanos más desfavorecidos ${ }^{39}$. Todo lo anterior debe estar motivado por el agradecimiento de los dones entregados por Dios y la responsabilidad que ello implica para la entrega del mensaje cristiano en los ambientes más vulnerables ${ }^{40}$.

En este contexto, es evidente que el jesuita chileno dirija su exigencia a los católicos de la clase acomodada, por eso les señala a los educadores que han de generar alumnos que sean conscientes que la transformación social se lleva a cabo por medio del ejemplo, la palabra, la acción y la oración. Se comprende que la responsabilidad social es una praxis que tiene como fin hacer más humana la vida social ${ }^{41}$.

Es por eso que Hurtado ubica junto al sentido social el sentido de responsabilidad, pues ambos se complementan para que el católico actúe, sabiendo que tiene una misión que asumir, la cual va más allá de su pertenencia al género humano, ya que debe responder a su vocación de cristiano. Al respecto señala

\footnotetext{
A. Hurtado, "Puntos de educación...", 267.

Cf. A. Hurtado, "El sistema pedagógico...", 124.

39 En este sentido el padre Hurtado urge a los católicos chilenos a llevar adelante una vida que sea conforme a la formación y educación que han recibido, cf. A. Hurtado, “EEs Chile un...”, 54; A. Hurtado, "Humanismo Social...”, 62.

40 Cf. A. Hurtado, "El orden social...", t. 1,193; 333. Cf. A. Hurtado, "El orden social...", t. 2, 188; 207.

41 Cf. A. Hurtado, “Misión del universitario...", 114.
} 
"no podrá llamarse soldado de Cristo el que no dé un sentido social a su vida, el que no se interese por sus hermanos. Para muchos, durante muchos años, el cristianismo ha sido un asunto puramente individual, algo así como una especie de seguro para la otra vida, o un consuelo para los momentos amargos de la vida... Pero el cristianismo auténtico no es eso: es la religión de los hermanos que se sienten responsables de la salvación de sus hermanos; es el amor de Cristo por los demás que los lleva a buscarles todos los bienes, sobre todo el gran bien de la fe; es la responsabilidad de una vida consciente de la parábola de los talentos, que impone a cada uno trabajar en la medida de la luz que ha recibido" ${ }^{2}$.

El sentido de responsabilidad es una actitud constante de cada persona, que se reconoce como protagonista de su vida y del devenir histórico en el cual se encuentra inmerso ${ }^{43}$. Para el padre Hurtado este sentido tiene que ver con la parábola de los talentos, porque el cristiano debe asumir que los dones, entregados por Dios, son para el servicio de toda la humanidad. Es por eso que el creyente, que reconoce el don de Dios en su vida, debe estar a la vanguardia en lo que se refiere al servicio de la sociedad y no puede marginarse de su responsabilidad. Además, este sentido de responsabilidad debe llevar a obras concretas, no puede ser solo una elucubración sobre la necesidad de ser serviciales hacia el próji$\mathrm{mo}^{44}$, debe traducirse en una actitud de respeto y amor hacia los demás, que se verá reflejada en la forma de trabajo y en la entrega de la actividad que le ha tocado realizar en la sociedad ${ }^{45}$.

42 A. Hurtado, “Cristo Rey...", 184-185.

43 En este sentido es interesante plantear la presencia de los otros en el horizonte personal no como una limitación de la libertad, sino como una llamada a un ejercicio más pleno de ella, ya que su presencia invita al ser humano a reconocer su responsabilidad de cara a las consecuencias de sus acciones, cf. L. Melina y otros, Caminar a la luz del amor. Los fundamentos de la moral cristiana (Palabra, Madrid 2007) 428-431.

44 Con respecto a la constatación práctica de la parábola de los talentos en distintos ámbitos de la praxis social, el padre Hurtado señala: "sentido de responsabilidad, que tiene tanto sabor evangélico en la parábola de los talentos [cfr. Mt 25,1430]: de aquí una conciencia profesional bien desarrollada; cumplimiento del deber a conciencia, no por pura rutina; suministro de mercaderías de buena calidad; adquisición de una verdadera competencia; lealtad en el servicio de los clientes; etc.". A. Hurtado, "Moral social...", 218.

45 En las reflexiones contemporáneas este tema se ha tratado como una ética de la responsabilidad, en ella se busca hacer que el hombre tome conciencia de su 
En síntesis, para Hurtado, el que se precia de ser cristiano, debe realizar obras que manifiesten su fe en la vida concreta, es decir, debe preocuparse por su prójimo, sobre todo si depende de él para su subsistencia. En este sentido, el católico no puede separarse del mundo y vivir como si no existieran las demás personas, porque desde la fe el otro se convierte en hermano ${ }^{46}$.

\subsection{Fundamentación antropológica}

La concepción del ser humano que subyace al pensamiento de san Alberto Hurtado se fundamenta teológicamente desde la condición de ser creado a imagen y semejanza de Dios, lo que se ve complementado con el Misterio de la Encarnación. Desde estos pilares, Hurtado desarrolla el tema de la responsabilidad social teniendo como telón de fondo la dimensión sobrenatural de la condición humana y la injerencia que ello tiene en el devenir de la sociedad.

De este modo, para el santo chileno, la condición creatural del hombre atraviesa y fundamenta la forma de relacionarse de los cristianos con todas las personas, ya que en cada una de ellas ha de contemplar las huellas del Creador, lo que desencadena la valoración profunda del reconocimiento del otro en su dignidad de ser hijo de Dios ${ }^{47}$. Alberto Hurtado no dudará en señalar que esta dignidad del ser humano "no reside en su raza, en el color de su piel, en su riqueza o nobleza, sino en la nobleza de ser creado a imagen y semejanza de Dios, hijo adoptivo suyo, hermano de Cristo, heredero del cielo" ${ }^{48}$. En este contexto, para el padre Hurtado el ser humano debe ser respetado, porque cada una de las personas es una expresión de la presencia de Dios mismo en la vida de la humanidad. De este modo, como creatura de Dios, es elevado

"a una grandeza que jamás el hombre podía sospechar: amigo de Dios: 'ya no os llamaré siervos sino amigos (Jn 15,15); templos donde Él habita: 'vendremos a él y haremos en Él nuestra morada' (Jn

relación con los demás y de las consecuencias de sus acciones, cf. J. FleCHA, Moral Social. La vida en comunidad (Sígueme, Salamanca 2007) 553.

46 Cf. A. Galindo, "El papel de la Iglesia en la promoción de la responsabilidad social empresarial. Problemas, soluciones y retos", en M. DE LA Cuesta - A. Galindo (coords.), Inversiones socialmente responsables (Publicaciones Universidad Pontificia de Salamanca, Salamanca 2005) 74-80.

47 Cf. A. Hurtado, "Puntos de educación...", 341.

48 A. Hurtado, "Marianita”, en S. Fernández (ed.), La búsqueda de Dios..., 164. 
14,23); elevados por participación a la vida divina, a la unión con el Creador, a vivir la misma vida de Dios por la gracia santificante: 'Yo soy la vid, vosotros los sarmientos' (Jn 15,5)"49.

La conexión entre los seres humanos y Cristo es de tal profundidad y magnitud, que ayuda a comprender en profundidad el misterio del hombre ${ }^{50}$, pues lo lleva a la plenificación por medio de la amistad, la inhabitación trinitaria y la santificación mediante la gracia. Todo ello debería llevar a los cristianos a poseer una estima muy elevada de todos sus congéneres ${ }^{51}$, a todo nivel y sin importar las condiciones en las que se desarrolle su existencia. De este modo, cualquier ayuda que se preste a uno de ellos, es a Dios mismo a quien se la brindan.

Otro aspecto relevante en la comprensión antropológica del padre Hurtado, es el motivo de la estadía del hombre en el mundo y el papel que juega la creación en este camino de acercamiento mutuo entre Dios y los hombres. Al respecto, señala que

"Para hacerlo su hijo, crea Dios al hombre; para divinizarlo por la gracia, para decir en él su Verbo; para unirlo tan íntimamente a la divinidad que la naturaleza divina estuviera en él presente, como la naturaleza del Padre está en el Hijo. Dios creó al mundo para el hombre, y el hombre para hacerlo su hijo, y para que pudiese, con verdad y con amor, llamarle a Él no solo Señor, sino también Padre. Porque el plan de Dios era que nos llamásemos y fuésemos hijos de Dios y lo seamos de absoluta verdad (cf. 1 Jn 3,1)"'52.

Para el padre Hurtado la creación del hombre no es casualidad, por cuanto se inserta en el plan de salvación que Dios ha dispuesto para él, busca la elevación del ser humano a una dignidad que le viene dada,

49 A. Hurtado, “Cristo Rey...", 180-181.

50 Es interesante constatar que Alberto Hurtado, ya en 1940 expresa esta realidad de la verdadera comprensión del misterio del hombre mediante la acción salvífica de Jesús, aspecto que quedará plasmado bellamente en la Constitución Gaudium et Spes del Concilio Vaticano II, cuando señala que "el misterio del hombre solo se esclarece en el misterio del Verbo encarnado", Concilio Vaticano II, Constitución pastoral sobre la Iglesia en el mundo actual: Gaudium et spes (BAC, Madrid 2000) 22.

51 Cf. A. Hurtado, "La joven y el amor", en S. Fernández (ed.), La búsqueda de Dios..., 199.

52 A. Hurtado, "El mundo contemporáneo y el sacerdote", en S. Fernández (ed.), La buisqueda de Dios..., 254. 
ya no solo por la creación ${ }^{53}$, sino por la participación de la vida divina mediante la gracia. Esta unión se ve ensalzada y fortalecida por medio de la Encarnación del Hijo y tiene por finalidad la toma de conciencia de la relación filial a la que está llamado el ser humano. Relación que le permite ver a Dios, ya no solo como el Creador, sino como un Padre amoroso, que se preocupa de la vida de cada uno de sus hijos ${ }^{54}$.

Para el jesuita chileno la creación es, en su conjunto, una instancia de conocimiento de Dios ${ }^{55}$, una primera forma de acercamiento a la presencia y realidad de Dios en la vida de los seres humanos, cada uno de los acontecimientos presentes en la existencia de la humanidad se evidencia como una palabra de Dios que viene a interpelar la fe de los creyentes. Es por eso que la pobreza, la miseria y el abandono de la persona serán, para el padre Hurtado, una señal de la necesidad que tiene la sociedad de la presencia de una comunidad de fe que se haga partícipe de las soluciones a las grandes amenazas que atentan contra la dignidad de la persona, sobre todo, en su calidad de hijo de Dios, llamado a un encuentro íntimo con su Creador que lo ama y que lo impulsa a ir más allá de las limitaciones de su existencia ${ }^{56}$. En este contexto, el ser humano está llamado a ser plenificado en medio de su vida cotidiana, donde cada una de las situaciones lo va conduciendo a la filiación divina, que ya ha sido donada por medio de la Encarnación de su Hijo. Por eso, el padre Hurtado no dudará en señalar que, por medio de este misterio, Cristo

"Unió tan íntimamente a sí la naturaleza humana que, por toda la eternidad, el hombre podrá decir: el Hijo de Dios se hizo hombre, tomó sobre sí nuestras debilidades, todas excepto el pecado (cf. Heb 4,15). Abajamiento: aparece 'apretado por las muchedumbres'; la Plenitud, aparece hambriento y sediento; la Santidad, es tratado de pecador; la Alegría eterna del Padre, acongojado hasta la muerte; jla Vida muere! ¡Por nosotros, los hombres, y por nuestra salvación!”’7.

53 Cf. A. Hurtado, "Principio y fundamento", en S. Fernández (ed.), Un disparo a la eternidad. Retiros Espirituales predicados por el padre Alberto Hurtado, s. j. (Ediciones Universidad Católica de Chile, Santiago 2002) 163.

54 Cf. A. Hurtado, "Cristo Rey...", 180-181.

55 Cf. A. Hurtado, "El mundo contemporáneo..., 254.

56 Cf. A. Hurtado, "In aeternum vivere: Vivir para siempre”, en S. Fernández (ed.), Un disparo a la eternidad..., 58.

57 A. Hurtado, “El mundo contemporáneo...", 255. 
Para el padre Hurtado la Encarnación es el misterio que lleva a la unidad profunda entre la naturaleza humana y divina, Jesús hace presente a Dios mismo en medio de la humanidad, no como una forma de acercamiento parcial, temporal, confuso, sino como un encuentro que perdurará hasta la vida eterna ${ }^{58}$. Cristo asume sobre sí todas las debilidades humanas, solo el pecado queda fuera de esta experiencia; asume la precariedad para conducir a la humanidad hacia el encuentro con Dios Padre y restaurar su dignidad lesionada por el pecado ${ }^{59}$.

Aquí se encuentra otro elemento de la antropología que subyace a la presentación del jesuita chileno, el pecado, que desvía al ser humano de su condición inicial y lo vuelve sobre sí mismo, como un ser incapaz de donarse y asumir el amor en la dimensión oblativa que enseña Jesús, por medio de su vida y su obra. De este modo, el pecado ejerce en el ser humano una nefasta labor, pues

"La razón y la fe nos llevan a Dios. Nuestra sensibilidad desordenada a la adoración de mi 'yo' y de las creaturas, a esa idolatría que considerábamos ayer como característica del pecado: Adorar la creatura en lugar del Creador" ${ }^{60}$.

Para Alberto Hurtado, el hombre, desde su creación, tiende a la búsqueda de Dios, tendencia que se ve afectada por el pecado ${ }^{61}$, en cuanto provoca en el ser humano un ensimismamiento de tal magnitud que le impide relacionarse con el Creador, buscando en las creaturas la compensación de su sed de trascendencia. De esta manera, realiza un giro hacia sí mismo y luego hacia el resto de las creaturas en un afán de pose-

58 Cf. C. Hodge, "Teología del Cuerpo Místico, antropología y moral social en san Alberto Hurtado. La influencia de Columba Marmión”, Teología y Vida 51 (2010) 591-593.

59 En la misma homilía Hurtado señala que: "Al morir Él, el muerto resucita... La deuda del pecado está pagada; el hombre puede de nuevo llamar a Dios su Padre... $\mathrm{Y}$ en su resurrección, en la de Cristo, comienza la resurrección de la humanidad: Primicia de los que duermen (cf. 1Cor 15,20)", A. Hurtado, "El mundo contemporáneo...", 255.

60 A. Hurtado, "La muerte", en S. Fernández (ed.), Un disparo a la eternidad..., 208.

61 En este sentido hay que señalar que para el padre Hurtado "lo peor es que cada pecado debilita más y más. A medida que uno persevera en el barro se hunde más y más, y se hace más difícil salir. El poder para el bien se hace cada vez más débil, el poder para el mal, el atractivo, las voces del pecado, cada vez más fuertes", A. Hurtado, "Morir, meditación sobre el pecado", en S. Fernández (ed.), Un disparo a la eternidad..., 50-51. 
sión que lo hace utilizar todo para su beneficio personal, situación que a la larga se transforma en su perdición, pues lo único que consigue es la soledad y generar más injusticia para sus congéneres provocando el odio y el desprecio de quienes se ven afectados por sus iniquidades ${ }^{62}$.

De cara a esta desgracia que implica el pecado en la vida del hombre, el padre Hurtado, siguiendo la tradición, señala la necesidad de un Salvador que restaure la antigua condición del ser humano y su cercanía con Dios; por eso no dudará en señalar que

"Ese Salvador, Dios en su misericordia, nos lo concedió. La segunda persona de la Santísima Trinidad se encarnó y la benignidad de Dios apareció en carne humana. En Jesús tenemos un hombre de nuestra raza que es a la vez Dios; tenemos un altar en que ofrecer un sacrificio: el Cuerpo de Cristo unido a la divinidad. Tenemos una víctima de valor divino y que los hombres pueden ofrecer por sí mismos, porque es uno de ellos. El sacrificio de Cristo, Jefe de la humanidad, salvará la humanidad. La suprema aspiración del hombre, ser Dios, podrá realizarse. Unidos nosotros a Él participaremos de la vida divina, oculta en esta tierra, sin velos en la gloria, herencia de los hijos, de los hermanos de Jesús, el Primogénito del Padre" ${ }^{63}$.

La misión redentora de este Salvador es una acción que entrega un nuevo impulso a la humanidad en su camino de reencuentro con Dios, lo acerca a Aquel que le ha donado la vida y le entrega un nuevo significado a su propia existencia. Proporciona a la humanidad la posibilidad de desarrollar una vida unida a Dios y participar de la vida divina por gracia, como un don libre y gratuito que nace del amor de Dios. Según San Alberto, el Salvador, conduce a la humanidad a la plenitud del desarrollo de sus potencialidades, haciendo al hombre hijo de Dios, por adopción, por medio de la unión que se da entre la humanidad y la divinidad en la persona de Jesús. Para Hurtado, la unión íntima del hombre con Cristo que se da por medio de la gracia ${ }^{64}$, es la que en definitiva transforma a la humanidad, conduciéndola a la máxima realización de sus aspiraciones y a la comprensión del misterio de su propia existencia ${ }^{65}$.

62 Cf. A. Hurtado, La crisis sacerdotal en Chile (Splendor, Santiago 1936) 155.

63 A. Hurtado, "La Eucaristía", en S. Fernández (ed.), Un disparo a la eternidad..., 297.

64 Cf. A. Hurtado, "Nuestra imitación de Cristo", en S. Fernández (ed.), Un disparo a la eternidad..., 84.

65 Cf. A. Hurtado, "Nuestra imitación de...", 79-85. 
Desde el sustento teológico de la Encarnación y de la unión que este misterio provoca entre Jesús y la humanidad, expresado por medio del Cuerpo Místico de Cristo al cual está llamado todo el género humano ${ }^{66}$, es que el santo chileno comprende la configuración del cristiano con Cristo como un aspecto fundamental de la vida de fe. Por este motivo exhorta constantemente a los creyentes

“'Ser Cristo! He aquí todo mi problema. La razón de ser de la creación'. Todo el mundo ha sido creado para la gloria del Hijo de Dios, y yo me uno al Hijo de Dios por mi bautismo, que me hace a mí también Hijo de Dios, y me vinculo más y más íntimamente cada vez que comulgo" ${ }^{67}$.

Para el jesuita chileno, el deseo de ser otro Cristo es la actitud que debería encender la vida de cada creyente, en el fuego de la caridad, que refresca la vida de una humanidad sedienta de amor y comprensión. Para esto es necesario estar unido a Cristo, lo cual se realiza por medio del sacramento del Bautismo, consolidándose y profundizándose en el acceso cotidiano al sacramento de la Eucaristía. Ambos sacramentos, son verdaderos canales que conducen la vida divina a la existencia de los creyentes y les permiten desarrollar la misión a la que han sido llamados: el amor a Dios que se manifiesta en el amor al prójimo ${ }^{68}$.

\subsection{Fundamentación sacramental}

Al finalizar el acápite anterior, se puede visualizar que Alberto Hurtado presenta la realidad bisacramental del Bautismo y de la Eucaristía como los canales que permiten al hombre acceder a la vida divina y, al mismo tiempo, configurarse con Cristo. Es por este motivo que afirma: " ¡Cada cristiano es otro Cristo! Cristo se ha multiplicado no solo por la

${ }^{66}$ Cf. A. Hurtado, "Cuerpo Místico: Distribución y uso de la riqueza", en S. Fernández (ed.), La búsqueda de Dios..., 151. Este tema ha sido profundizado en los estudios de C. Hodge y F. Parra; cf. C. Hodge, "Teología del Cuerpo...", 594-595; cf. F. Parra, “Teología del Cuerpo Místico, Comunión de los Santos y pensamiento social en San Alberto Hurtado. La influencia de Émile Mersch y Karl Adam", Teología y Vida 50 (2009) 802.

67 A. Hurtado, "El obstáculo mayor del optimismo", en S. Fernández (ed.), La buisqueda de Dios..., 91.

68 Cf. S. Fernández, "'Ya no vivo yo, es Cristo que vive en mî' (Gál 2, 20). 'Ser Cristo' como clave de la vida del padre Alberto Hurtado”, Teología y Vida 45 (2005) 352-373. 
Eucaristía, sino también por nuestro bautismo. Cristo vive en nuestros prójimos" ${ }^{9}$. De este modo, cada cristiano es la presencia real de Cristo en la historia, es decir, lo convierten en un receptor y canalizador del amor de Dios a los más pobres, pues el otro se presenta como Cristo reconociéndolo como prójimo en cuanto persona dotada de dignidad y al cual está llamado donarse generosamente, hasta entregar incluso su vida para el bienestar del otro.

En síntesis, para el jesuita chileno, el sacramento del Bautismo le entrega la fundamentación teológico/sacramental que le permite exigir una actitud de responsabilidad social a todos los creyentes, por eso señalará que

"Cada cristiano por el bautismo adquiere una responsabilidad personal y social. Responsabilidad personal de aplicar a su vida la verdad que posee: el curso (de religión) ha de ser un llamado continuo a superar la mediocridad. Responsabilidad social, que exige la entrega de su vida al servicio de los demás" ${ }^{\prime 70}$.

Para Alberto Hurtado uno de los efectos del bautismo es la responsabilidad, que en este caso es presentada en una unidad inseparable, es, por un lado, personal y, por otro, social, es decir, una responsabilidad hacia la propia existencia, en el sentido de vivir lo que se profesa y, a partir de ello, consagrarse en el servicio a los demás seres humanos. El fiel bautizado ha de ser una persona que viva atenta a las circunstancias de la vida social, sabiendo que allí debe hacer palpable la presencia real de Cristo.

Fundamentar la Responsabilidad Social en el Bautismo le permite, al santo chileno, sostener que la praxis social responsable no es un sobreañadido a la fe sino que es parte fundamental de su vivencia. Es por este motivo que Hurtado sostiene que la responsabilidad social debe ser enseñada y promovida, así no dudará en afirmar que la asignatura de Religión en la enseñanza secundaria debería aspirar

"a dar un sentido íntimo de responsabilidad social, que ha de traducirse en la elección del estado de vida, que le permita expansionar más íntimamente su vida cristiana y colaborar en forma más eficiente a la expansión del Reino. Ser cristiano significa

69 A. Hurtado, "La joven y...", 199.

70 A. Hurtado, "La enseñanza de...", 200. 
manifestar la vida de Cristo en todas las actividades, hacer que Cristo llegue a la estatura completa. El mundo necesita como solución para sus problemas, incluso los más humanos, de Cristo y de su doctrina, único fundamento de un orden social justo"71.

Para el padre Hurtado la responsabilidad social ha de iluminar toda la vida del creyente, incluso la elección de su estado de vida, pues todo lo que el cristiano realiza repercute en la sociedad y en medio de ella debe manifestar de modo real la presencia de Cristo. Esto solo se hará a través de la acción de los cristianos, porque su actuar es necesario en la expansión del Reino de Dios. Por eso, cada una de sus actividades cotidianas es una ocasión de hacer presente el amor de Dios en medio de la humanidad. Para Hurtado, la Responsabilidad Social se desarrolla en la intimidad de la vida del creyente y le permite responder con generosidad a la vocación a la que Dios lo llama. De allí se entiende que el apostolado social sea una motivación para la elección vocacional; así lo señala en un informe cuando dice que

"La mayor parte de nuestros jóvenes ha decidido su vocación por una convicción de responsabilidad social en sentido amplio. Creo que una intensificación de un apostolado social aquietaría incluso a muchos jóvenes que suspiran hoy por las misiones"72.

Para el padre Hurtado existe una directa relación entre el apostolado social y el aumento de las vocaciones sacerdotales. No tiene dudas de que cuando la Iglesia se acerca a las problemáticas humanas profundas, no de forma teórica sino con una presencia y compromiso claros, las respuestas generosas a la vocación sacerdotal surgen casi de forma espontánea. Al respecto, le decía al Papa Pío XII que

"Si se viese a la Iglesia más comprometida en la solución de los problemas humanos, se podría realmente esperar que hubiese más vocaciones, porque en realidad puedo atestiguar que la mayor parte de las vocaciones de estos últimos años han sido suscitadas sobre todo por el hecho de su responsabilidad social"73.

Una Iglesia comprometida con los problemas de la humanidad es, para el jesuita chileno, la garantía de la mayor presencia de vocaciones

\footnotetext{
71 A. Hurtado, "La enseñanza de...”, 212.

72 A. Hurtado, "Informe al P. Álvaro Lavín...”, 196.

73 A. Hurtado, "Memorial presentado al...", 201.
} 
sacerdotales en medio de la crisis vocacional, que él veía en sus tiempos de apostolado ${ }^{74}$. Lo que Hurtado persigue es una Iglesia que se muestre ante la humanidad realmente encarnada, conocedora de todas las circunstancias de alegría y fracaso que enfrentan los seres humanos, y que, en medio del dolor, se muestre misericordiosa y cercana con cada uno de los seres humanos a los que está llamada a servir. Este aspecto dará el verdadero sentido a la misión del sacerdote: vivir junto a los hombres y compartir todas sus vicisitudes, para desde allí conducirlos al encuentro con el Padre ${ }^{75}$.

\section{La Responsabilidad Social a la luz de San Alberto Hurtado}

Tomando en cuenta los fundamentos de la responsabilidad social, se puede comprender la definición de la misma, que contiene el libro póstumo del padre Hurtado "Moral social", donde el santo chileno señala que "La responsabilidad social: que dice bien claro que no puede uno contentarse con no hacer el mal, sino que está obligado a hacer el bien y a trabajar por un mundo mejor" ${ }^{27}$.

En estas breves líneas se contiene la profundidad del concepto responsabilidad social en el pensamiento del jesuita chileno, pues centra esta actitud en la beneficencia, dejando como un paso menor la no maleficencia. Para Hurtado, el católico no puede contentarse, simplemente, con no hacer daño, pues eso, si bien es lo mínimo, no se acerca a la actitud de fe que un cristiano debería manifestar ${ }^{77}$, es decir, realizar el bien a toda la humanidad.

Definir la responsabilidad social tal como lo plantea el santo chileno, requiere tener presente cuatro elementos fundamentales que se proponen como fruto del análisis del concepto a modo de proporcionar una definición tipológica, a saber: la dignidad, la comunidad, la fraternidad y la participación.

74 Cf. F. JimÉnEz, "El lugar de la Iglesia en el mundo moderno. Una mirada cronológica a las vocaciones sacerdotales, los laicos y los pobres en el ministerio de San Alberto Hurtado, S.J.”, Teología y Vida 51 (2010) 524-528.

75 Cf. A. Hurtado, "Elementos de vida espiritual", en S. Fernández (ed.), La buisqueda de Dios..., 31.

76 A. Hurtado, "Moral social...", 205.

77 Cf. A. Hurtado, "El deber de la Caridad", en S. Fernández (ed.), Un fuego que enciende otros fuegos (Ediciones Universidad Católica de Chile, Santiago 2004) 104. 
Desde la Antropológica Teológica el fundamento de la responsabilidad social es el reconocimiento de la dignidad de la persona que, para Hurtado, se fundamenta en la justicia y en la caridad ${ }^{78}$. Por eso no es extraño que el jesuita chileno tenga en tan alta estima el hecho de practicarla en términos de beneficencia, lo cual se desprende desde el evangelio, cuando resuenan en sus oídos las palabras del Maestro: "Por tanto, todo cuanto queráis que os hagan los hombres, hacédselo también vosotros a ellos. En eso consisten la Ley y los Profetas"79.

De este modo, el concepto de responsabilidad social desarrollado por Alberto Hurtado está claramente direccionado a conseguir que la vida de la persona sea más humana, en tanto se acerque al plan que Dios tiene preparado para cada hombre: una existencia iluminada y traspasada por el amor de Dios, manifestado en Cristo, y concretizado en la vida de las personas por medio de las acciones de los cristianos. Por eso el amor, que es la regla de convivencia de los cristianos, ha de traslucirse en bien, en la búsqueda del bien común, no solo como un deseo, sino como una realidad, que se plasmará en obras que trasciendan la vida de quienes las realizan ${ }^{80}$.

El cristiano es un constructor de la historia, por eso entiende que las problemáticas sociales actuales se deben a la presencia activa o a la omisión que hacen los católicos en la vida pública ${ }^{81}$. La presencia tan abultada del mal es producto de la ausencia de la acción benéfica de los cristianos en la sociedad; acciones que están llamados a realizar desde el momento de abrazar la fe. El bautismo imprime la misión del bien en la vida de los cristianos, dado que en este sacramento se ha recibido el mayor don que un hombre puede acoger: ser hijo de Dios y con ello la misión de amar a la humanidad como Dios la $\mathrm{ama}^{82}$. Esta es la responsabilidad intransferible que se asume desde la fe, de allí la urgencia que el

Cf. A. Hurtado, "Humanismo social...", 88.

Mt 7,12.

80 Cf. J. Castellón, Padre Alberto Hurtado, S. J. Su espiritualidad (Don Bosco S. A., Santiago 1998) 24-26.

81 Cf. M. Vidal - P. Santidrian, Ética social y politica (Paulinas/Verbo Divino, Madrid 1981) 23-27.

82 Cf. E. Jiménez, Moral eclesial. Teología moral nueva en una Iglesia renovada (DDB, Bilbao 1989) 212-222. 
padre Hurtado tiene en la formación y toma de conciencia de la responsabilidad social por parte de cada uno de los creyentes ${ }^{83}$.

El segundo concepto que se propone para comprender la responsabilidad social es la dimensión comunitaria, que para Hurtado se plasma principalmente en la vida eclesial pues, el cristiano debe ser un colaborador constante en el crecimiento del hombre y no puede marginarse de su papel protagónico en la defensa de la dignidad de la persona. La doctrina cristiana, no puede ser una especie de piedra filosofal que sirva solo para entregar buenas recomendaciones y que con eso se tranquilice la conciencia de los creyentes; por el contrario, debe servir y operar en la existencia concreta de cada uno y traslucirse como un prisma que ilumine la vida de la sociedad ${ }^{84}$.

Para el jesuita chileno, la fe no es un refugio que le permita al cristiano llevar una vida sin sobresaltos ni problemas y así no hacer peligrar su salvación. Al contrario, para Hurtado la fe y la salvación se realiza principalmente insertándose en la vida social, esto constituye la expresión de la fe auténtica, sobre todo, en el servicio a los más necesitados. Es necesario aclarar que el santo chileno no desprecia a los ricos, sino que les hace un llamado a que estén atentos a las necesidades de quienes menos poseen, pues son los administradores de los bienes materiales que Dios les confió. En este caso, la responsabilidad social se acrecienta con la abundancia de bienes materiales ${ }^{85}$.

Esta dimensión comunitaria se fundamenta en la comunión de los santos la cual se comprende de manera más amplia, pues no solo la restringe a bienes espirituales, sino que el padre Hurtado llama a quienes han sido más favorecidos a compartir sus bienes para que puedan descubrir su verdadera dignidad de ser hijo de Dios y, desde allí, busquen aquello que les permita desplegar el máximo de potencialidades que provienen de este don tan inmenso ${ }^{86}$. En perspectiva, se debe señalar que Alberto Hurtado no excluye de la responsabilidad social a los pobres, puesto que la escasez de bienes materiales no significa eximirse de aquella responsabilidad que nace de la propia dignidad, de la propia realidad

83 Cf. J. Costadoat, El talante social en la espiritualidad del p. Hurtado (Centro de Estudios Ignacianos, Santiago 1995) 18-19.

84 Cf. T. Mifsud, Propuestas éticas hacia el siglo XXI (San Pablo, Santiago 1993) 67-74.

85 Cf. A. Hurtado, “¿Es Chile un...”, 54.

86 Cf. F. Parra, “Teología del Cuerpo...”, 818-820. 
de ser hijo de Dios, y allí, en el pequeño lugar que ocupa, está llamado a ser el protector y ayudador de sus hermanos ${ }^{87}$.

Ahora bien, tanto la dimensión de la dignidad de la persona como la comunitaria, se concretan en dos actitudes claves, a saber: la fraternidad y la participación social.

De este modo, para el padre Hurtado, la fraternidad es un punto central de la actuación de los cristianos en la sociedad, porque ella nace de la convicción de llevar el amor de Dios a todos los seres humanos ${ }^{88}$. La realización del amor fraternal es, para el jesuita chileno, una convicción profunda, que lo lleva a pensar que solo desde esta forma de ver la vida social se puede encaminar a los creyentes a la verdadera construcción de la fraternidad querida por Dios para todos sus hijos ${ }^{89}$, especialmente para los pobres ${ }^{90}$. Esta convicción se apoya en discursos y documentos de algunos obispos católicos que lee y que son para él fuente de inspiración. Uno de ellos es el llamado que hace el episcopado de Inglaterra, en 1942, donde se señala que "Si Dios es verdaderamente el Padre de todos nosotros, nuestro primer deber es de rendirle homenaje y de amarlo y nuestro segundo deber es de amarnos los unos a los otros como hermanos" ${ }^{\prime 1}$.

De esta manera, Hurtado invita a practicar la fraternidad universal entre los seres humanos y comprender que no se puede olvidar que Dios ha fundado la humanidad como una gran familia, en la cual todos están emparentados mutuamente, por ser creados a imagen y semejanza de Dios. Todo ello se ha visto reforzado con la Encarnación del Hijo de Dios, de forma que los hombres ya no solo son hijos de Dios por ser creados, sino que son hijos de Dios porque su propio Hijo ha asumido la naturaleza humana, de tal forma que el destino del ser humano está marcado por el amor de Dios. De esta manera, surge en la humanidad una nueva forma de relación, que va más allá de la simpatía, la raza, la posición social, la educación, la nación en la que se vive, es una unión que rompe todas las barreras que el individualismo levanta entre las dis-

87 Cf. A. Hurtado, “¿Es Chile un...”, 51-52.

88 A. Hurtado, "Humanismo social...", 14.

89 Cf. T. Mifsud, El sentido social: el legado ético del padre Hurtado (Ignacianas, Santiago 2005) 71.

90 Cf. J. Costadoat, "El talante social...", 19-21.

91 A. Hurtado, "El orden social..., t. 2", 277. 
tintas personas, pues todos los seres humanos son hijos de Dios y están llamados, por amor, a la comunión entre ellos. Esta vocación crea de forma natural la fraternidad entre los hombres, por su filiación divina. En este contexto no es difícil comprender que el padre Hurtado sea enfático en señalar que frente a las necesidades de los hombres en el ámbito social, "la actitud católica, que no es de lucha ni de abstención, sino de sincera colaboración social; su meta es realizar en la práctica la verdadera y auténtica fraternidad humana" ${ }^{92}$.

Una segunda actitud esencial en la vida social es para el padre Hurtado la participación, como actitud indispensable para actuar de modo socialmente responsable, al respecto señala

"La actitud del católico en materia social debe ser la de luchar en primera fila, y esto no por miedo al comunismo, sino por amor a Cristo y a los hombres, sus hermanos. Aunque no hubiera nacido Karl Marx ni Lenin, aunque Rusia estuviera bajo el régimen de los zares, si hay un pobre que sufre injusticias, tengo una obligación con él. Tengo una deuda de la que no puedo declararme libre hasta que la haya pagado. Social no por anticomunista, sino que social porque católico" ${ }^{\prime 3}$.

El mayor problema al que se ve enfrentada la enseñanza de la fe es la indolencia que manifiesta parte de la humanidad frente al sufrimiento del resto de sus hermanos ${ }^{94}$. A tanto llega este desconocimiento del dolor humano que algunos poseen la concepción de la existencia de una clase social que siempre estará bajo el signo del dolor ${ }^{95}$ y que es imposible el alivio de dicha experiencia ${ }^{96}$. En este contexto, el padre Hurtado siente la urgencia de señalar que los católicos han de asumir el protagonismo social, al que los catapulta su fe, y ponerse en la primera línea de la defensa de los derechos propios de la persona humana. Desde aquí se entiende que, para Hurtado, allí donde haya un hermano que esté viviendo en condiciones que lesionan su dignidad, el cristiano no pueda

\footnotetext{
A. Hurtado, "Humanismo social...", 11-12.

93 A. Hurtado, "La misión social del universitario", en S. Fernández (ed.), La búsqueda de Dios..., 105.

94 Cf. A. Hurtado, "Humanismo social...", 27-28.

95 Cf. J. GomÁ, Ejemplaridad pública (Taurus, Madrid 2009) 16; cf. S. Pinker, La tabla rasa. La negación moderna de la naturaleza humana (Paidós, Barcelona 2003) 173.

96 Cf. A. Hurtado, "Humanismo social...", 117.
} 
quedarse tranquilo97. Por eso, en su concepción de la participación de los cristianos en la vida social, la principal motivación para el actuar social no es oponerse a los enemigos, sino que la acción social surge de lo más profundo del ser creyente, respecto de lo cual dirá que se es social por ser católico y que este ser conlleva una vivencia protagónica en el ámbito social. El gran problema, afirma Hurtado, es la tibieza que se manifiesta en la vivencia de la fe de parte de muchos católicos ${ }^{98}$. Por eso no duda en señalar que "mientras los cristianos no encarnen en sus corazones y en sus obras la concepción de los hombres que tuvo el Maestro, el pueblo vivirá alejado de la Iglesia" ${ }^{\prime}$.

Para el padre Hurtado, la falta de conciencia de la responsabilidad social está asociada al temperamento latino que marca la realidad de la sociedad chilena, porque en ello ve una falta de seriedad que no se aprecia en aquellos pueblos que son más bien de temperamento que él denomina sajón, pues este carácter les haría ser más reflexivos, templados y conscientes de sus acciones, aspecto que se ve profundamente alejado de la idiosincrasia dominante en Chile, que es más ardiente, más impetuosa, más sensible y menos reflexiva que los sajones. Tristemente comprueba, el jesuita chileno, que los jóvenes no se toman nada en serio, se burlan de las situaciones que no comprenden, buscan en su actuar la comodidad y el agrado. Todo lo anterior se ve expresado en la falta casi absoluta de formalidad, de reflexión, de profundidad, de puntualidad, de conciencia de las obligaciones sociales, de valorización de la cosa en sí misma. Esto se manifiesta claramente en la desobediencia que los jóvenes tienen a las orientaciones que les son entregadas por sus padres, maestros y directores espirituales ${ }^{100}$.

El camino de solución que propone el jesuita chileno es estar atento a las realidades sociales en las cuales se desarrolla la vida del creyente. A esta condición se accederá por medio de una formación integral de

\footnotetext{
Cf. A. Hurtado, “¿Es Chile un...”, 51.

Cf. A. Hurtado, “¿Es Chile un...”, 95.

A. Hurtado, “¿Es Chile un...”, 55.
}

$100 \mathrm{Al}$ respecto Hurtado señala que "la impresión general que dejan nuestros adolescentes es la de no tomar nada en serio, la de burlarse de las situaciones y buscar en todo el aspecto comodidad, agrado, inconscientes de la responsabilidad social que les incumbe. Muchos, muchísimos parecen concebir la vida como un estadio en el que uno ha de divertirse con el maximun de intensidad y el minimun de sacrificio", A. HurTado, "La psicología del...", 66. 
la persona en todas sus dimensiones y actividades. En este contexto, se comprenden sus palabras sobre la meditación y la forma en que ella contribuye al desarrollo de la conciencia de la responsabilidad social, por eso son muy interesantes las reflexiones que plantea cuando vislumbra los senderos que se han de recorrer para superar la inconsistencia que se presenta en la juventud de su época. Refiriéndose a la meditación, señala que

"Después de la lectura, y complemento necesario de ella, es la meditación, esto es el repensar una verdad, el mirarla bajo todos sus aspectos, el ejercitar en ella armónicamente todas las facultades de nuestra alma: la memoria recordando, la inteligencia discurriendo, la voluntad afectándose a propósito de los hechos fundamentales de la vida, por ejemplo el sentido de mi vida, el origen de mi ser, el fin de mis actividades, mi responsabilidad social, el concepto de deber, de felicidad, un acontecimiento mío, o un hecho público, una conferencia que he escuchado, el problema del hogar, la formación de mi carácter, mi elección de carrera, temas fundamentales sobre los que debiera pensar una y muchas veces"101.

De este modo, la responsabilidad social es un acto que surge desde la reflexión y planificación del actuar, no es simplemente una reacción frente a determinadas situaciones puntuales. Ella es una tarea reflexiva que busca comprender con mayor profundidad la propia existencia y la sociedad en su conjunto. Desde allí se entiende que la responsabilidad social posee un doble ámbito de participación donde deben actuar los creyentes: el civil y el religioso ${ }^{102}$. En el primero, se busca despertar una actitud de vigilancia para estar atento a las necesidades de la propia nación donde se vive y de la humanidad en su conjunto como una gran familia. Y, en lo que se refiere al ámbito religioso, se persigue ser consciente de la responsabilidad que cada uno de los católicos tiene: de ser verdadero testimonio de la presencia de Cristo en el mundo ${ }^{103}$.

\section{Conclusión}

$\mathrm{Al}$ aproximarse al concepto de responsabilidad social desde la perspectiva de san Alberto Hurtado se vislumbra la necesidad de liberar el

101 A. Hurtado, "Cómo remediar la...", 91.

102 Cf. A. Hurtado, "Lo que ha...", 308.

103 Cf. A. Hurtado, "Nuestra imitación de...”, 82. 
concepto de su enclaustramiento economicista, para devolverlo a todos los ámbitos de la vida de las personas. En este contexto, la propuesta del jesuita chileno en torno al actuar social de los creyentes permite entregar un fundamento sólido a la responsabilidad social que esté orientada desde la centralidad de la persona como agente moral. Este aspecto permitirá situar el tema más allá de la miopía economicista ${ }^{104}$ en que se ha centrado la reflexión, pues muchas veces se presenta el quehacer empresarial como si fuese el único ámbito de acción humana en donde es exigible un comportamiento socialmente responsable.

En este horizonte, el pensamiento social de san Alberto Hurtado, expresado por el torrente de la responsabilidad social, es un aporte para ampliar las reflexiones sobre el tema, situando en el centro de la acción socialmente responsable a la persona, ensanchando de este modo la comprensión de la trascendencia humana y las consecuencias sociales de su existencia. Desde el pensamiento del jesuita chileno surgen líneas de reflexión que permiten profundizar el ámbito de la responsabilidad social pues, situar el acento en la persona y no en la institución se presenta como una novedad para las reflexiones que hoy se desarrollan en torno al tema, es una novedad que siempre estuvo presente pero que no se ha presentado con la claridad que se requiere para dar más armonía a la convivencia social ${ }^{105}$.

Hay que destacar el horizonte de la beneficencia en el que Hurtado ubica la responsabilidad social, pues ella amplía y profundiza una realidad que se extraña en muchas reflexiones con respecto al tema, pues en su gran mayoría pareciera que la no maleficencia es a lo más magnánimo que se puede optar en el desarrollo de una conducta socialmente responsable y no se busca más, pues en muchas de las posturas que se refieren al tema lo que interesa es que la empresa desarrolle su labor sin perder

104 Cf. J. Garmendia, "Qué quiere decir y para qué sirve la responsabilidad social corporativa”, en: J. Almagro y otros (coords.), Responsabilidad social. Una reflexión global sobre la RSE (Pearson, Madrid 2010) 6.

105 Este aspecto es parte de la propuesta de la tesis doctoral "La responsabilidad social en el pensamiento de San Alberto Hurtado Cruchaga", presentada en la Pontificia Universidad de Salamanca. En ella se plantea la necesidad de incorporar una responsabilidad social de corte personal a los conceptos de RSE/RSC, cf. J. Aros, La responsabilidad social en el pensamiento de San Alberto Hurtado Cruchaga (Salamanca 2017) 181-191. 
de vista la finalidad que es la consecución de rentabilidades favorables para los inversores ${ }^{106}$.

Con respecto a la fundamentación de la centralidad de la persona que Hurtado muestra en su propuesta de responsabilidad social, vale la pena hacer mención a los fundamentos teológicos que sustentan el desarrollo de su pensamiento en este ámbito, es decir, los aspectos antropológicos, bíblicos y sacramentales que orientan la acción de los creyentes en la vida social, dimensiones que son claves al momento de solicitar una acción más comprometida socialmente por parte de los cristianos.

Por su parte, las dimensiones que se desprenden desde su pensamiento para el desarrollo de la responsabilidad social personal, son aspectos que van más allá del ámbito de la fe puesto que la dignidad de la persona, la comunidad humana en la cual se desenvuelve, la fraternidad entre los miembros del género humano y la participación que la persona debe desarrollar en la vida social, son aspectos que se pueden solicitar a todos los seres humanos sin importar las condiciones de su vida, ni sus opciones religiosas. Hurtado, al devolver la responsabilidad social al ámbito personal incluye a cada uno de los seres humanos en la búsqueda de una mejor sociedad y de un porvenir acorde a su dignidad, desde sus palabras se puede afirmar que nadie queda excluido del desarrollo de una conducta socialmente responsable. Pues, no es necesario ser un agente económico de mayor cuantía para tomar conciencia de la responsabilidad social de las acciones que cada uno realiza.

En este sentido se puede afirmar que, con respecto a la responsabilidad social, San Alberto Hurtado es un prisma que permite ampliar y diversificar el espectro de realidades humanas que este concepto abarca en las reflexiones que hoy se desarrollan en torno a este tema. Pues para el santo chileno la responsabilidad social es hacer el bien y trabajar por un mundo mejor, donde se busque proteger y relevar la dignidad de la persona, su vida comunitaria, para lo cual es imprescindible una actitud de fraternidad y participación que manifieste la plena integración del cristiano a la vida social.

106 Cf. J. Herranz, "La comunicación de...”, 95; cf. B. FernándeZ, "Inversión socialmente responsable...", 131-132; cf. F. Navarro, Responsabilidad Social Corporativa: Teoría y práctica (ESIC, Madrid 2012) 351; cf. T. RodríGuez - T. Alberich - Á. Espadas, "Responsabilidad social corporativa, sostenibilidad y alternativas locales de desarrollo", en: J. Almagro y otros (coords.), Responsabilidad social..., 179-181. 